Supporting Information for

\title{
Enhanced Carbon Capture through Incorporation of Surfactant
}

\section{Additives}

Jonathan J. Bryant ${ }^{1}$, Cameron Lippert ${ }^{1}$, Guojie Qi ${ }^{1}$, Kun Liu ${ }^{1}$, David S. Mannel ${ }^{1}$, Kunlei Liu ${ }^{1,2, *}$

1. Center for Applied Energy Research, University of Kentucky, 2540 Research Park Drive, Lexington, KY 40511, United States

2. Department of Mechanical Engineering, University of Kentucky, Lexington, KY 40506, United States

*Corresponding Author

Tel: +1 8592570293 (Kunlei Liu)

E-mail address: kunlei.liu@uky.edu (Kunlei Liu) 


\section{General}

$\mathrm{CO}_{2}$ capture experiments were performed using National Instruments LabVIEW 2010 software. Gas flow rates were controlled by mass flow controllers (Aalborg), and the outlet $\mathrm{CO}_{2}$ concentration was monitored with a Horiba VIA-510 $\mathrm{CO}_{2}$ analyzer.

\section{Materials and methods}

Monoethanolamine (99\%, technical grade) was purchased from Univar (Redmond, WA, USA). Surfactant S-554 was obtained from ChemGuard. $\mathrm{CO}_{2}\left(99.5 \%\right.$, welding grade) and $\mathrm{N}_{2}(99.999 \%$, ultra-high purity) gas cylinders were supplied by Scott Gross (Lexington, KY, USA). $\mathrm{CO}_{2}$ analyzers are from HORIBA (VIA-510, $0.5 \%$ precision).

\section{Carbon loading measurements ( $\mathrm{mol} \mathrm{C} / \mathrm{mol} \mathrm{N})$}

The total inorganic carbon (mol C) was measured using an in-house carbon loading apparatus described previously by our group. ${ }^{1}$ Briefly, the apparatus consists of a reservoir containing an acid solution with an inlet and outlet for gas to bubble through and a sampling port fitted with a septum. The sample to be measured is injected through the sampling port, and the inorganic carbon reacts with the acid to form gaseous $\mathrm{CO}_{2}$. $\mathrm{N}_{2}$ as a carrier gas is bubbled through the solution, and the outlet gas is carried to $\mathrm{a}_{2}$ analyzer.

The alkalinity value $(\mathrm{mol} \mathrm{N})$ was determined by an acid-base titration using an automatic titrator (Metrohm Titrando 836). The titrant was $0.1 \mathrm{M}$ sulfuric acid.

\section{Surface tension measurements}

Surface tension was measured using a capillary tube. The capillary tube was immersed in the solution to be measured, and the distance that the solution traveled up the tube was recorded. The surface tension $(\gamma)$ was then calculated according to Eq. S1

$$
\gamma=\frac{1}{2} h r \rho g
$$

where $h$ is the height traveled by the liquid, $\mathrm{r}$ is the radius of the capillary tube, $\rho$ is the density of the solution, and $g$ is the acceleration due to gravity.

\section{Packed column (miniscrubber)}

A packed column, or miniscrubber, was used to test the $\mathrm{CO}_{2}$ absorption enhancement by surfactant. Figures S1 and S2 show a schematic and a picture of the miniscrubber system, respectively. The column is $1.59 \mathrm{in}$. in diameter with an effective packing height of $21 \mathrm{in}$. Ceramic Raschig rings $(6 \mathrm{~mm} \mathrm{OD} \times 3 \mathrm{~mm}$ ID $\times 6 \mathrm{~mm}$ height $)$ were used as the random packing material.

In the miniscrubber system, an upstream feed gas of $\mathrm{CO}_{2}$ and $\mathrm{N}_{2}$ is passed countercurrently to a downstream solvent flow through a column filled with random packing (ceramic Raschig rings). 
The system has two solvent reservoirs; valves are used to pump the solvent from reservoir 1 through the column and into reservoir 2 . The amount of solvent in the reservoir depends on the desired liquid flow rate, which is controlled by the pump. The solvent flows over the packing, absorbs $\mathrm{CO}_{2}$, and eventually reaches a steady state, at which point a sample is collected and the data are recorded for that given cycle. The $\mathrm{CO}_{2}$-loaded solvent is then directed from reservoir 2 back to reservoir 1 for the next cycle. This cyclic process is repeated to determine the $\mathrm{CO}_{2}$ absorption performance at different $\mathrm{CO}_{2}$ loadings.

In these tests, the $\mathrm{CO}_{2}$ concentration was $14 \%$, and the total gas flow rate was set to $17.3 \mathrm{~L} / \mathrm{min}$. The liquid flow rate was set to $155 \mathrm{~mL} / \mathrm{min}$. The desired gas and liquid test temperature was $40{ }^{\circ} \mathrm{C}$. The $\mathrm{CO}_{2}$ capture efficiency was calculated using the gas flow rate and inlet and outlet $\mathrm{CO}_{2}$ concentrations. The total alkalinity and carbon loading of the liquid samples from each cycle were determined by titration and a $\mathrm{CO}_{2}$ loading testing apparatus using an acid wash method, respectively.

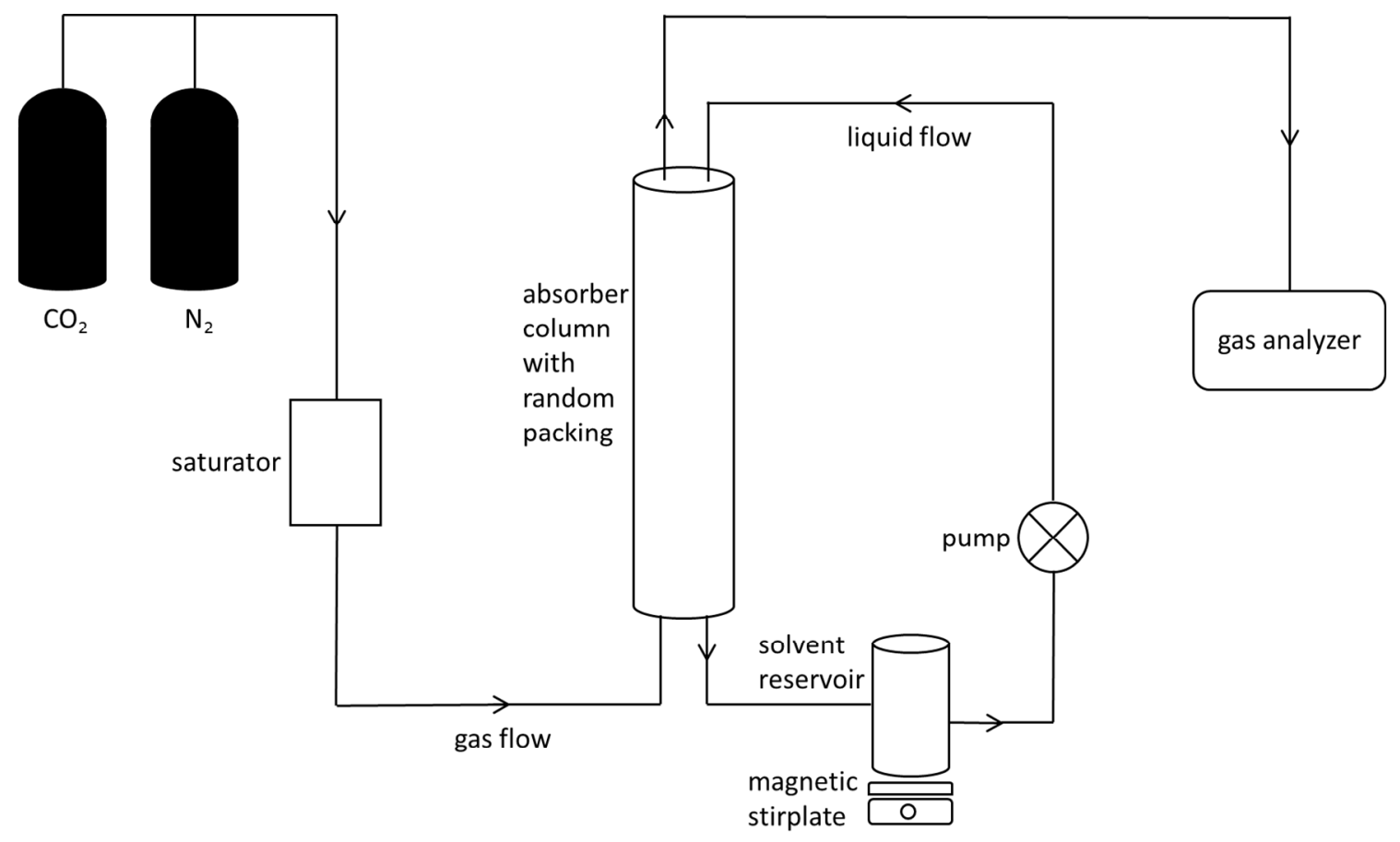

Figure S1. Schematic of the packed column (miniscrubber) experimental setup. 


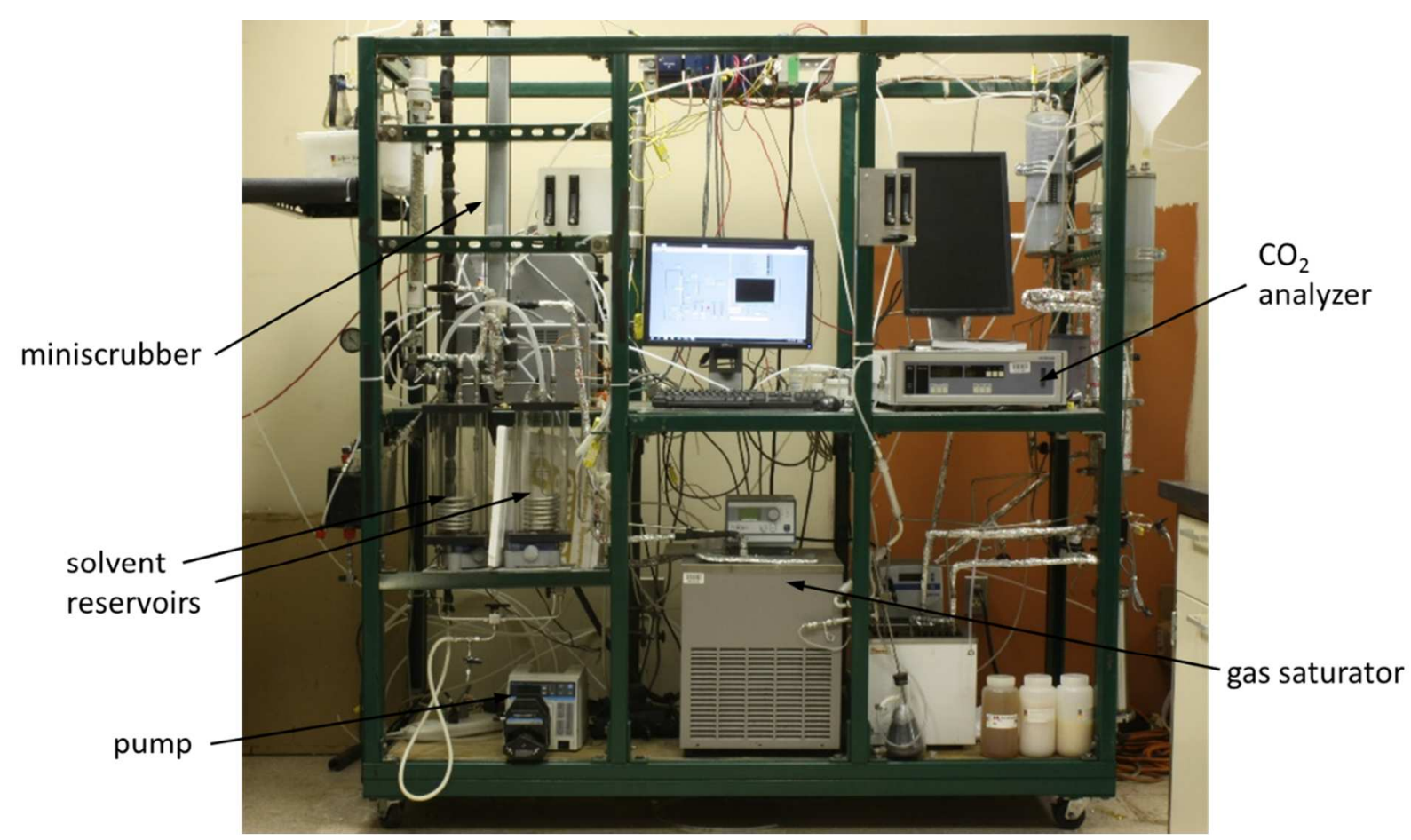

Figure S2. Picture of the miniscrubber system.

Solutions containing various amounts of surfactant (and thus having different surface tensions) were run through the miniscrubber. After calculating the capture efficiency at different carbon loadings for each solution, the increase (compared to $30 \mathrm{wt} \%$ MEA) was plotted as a function of the decrease in surface tension (Figure S3). No correlation was found. The increase in efficiency and the decrease in surface tension were calculated using the values expected from $30 \mathrm{wt} \%$ MEA. Calibration curves were made for this purpose (Figure S4).

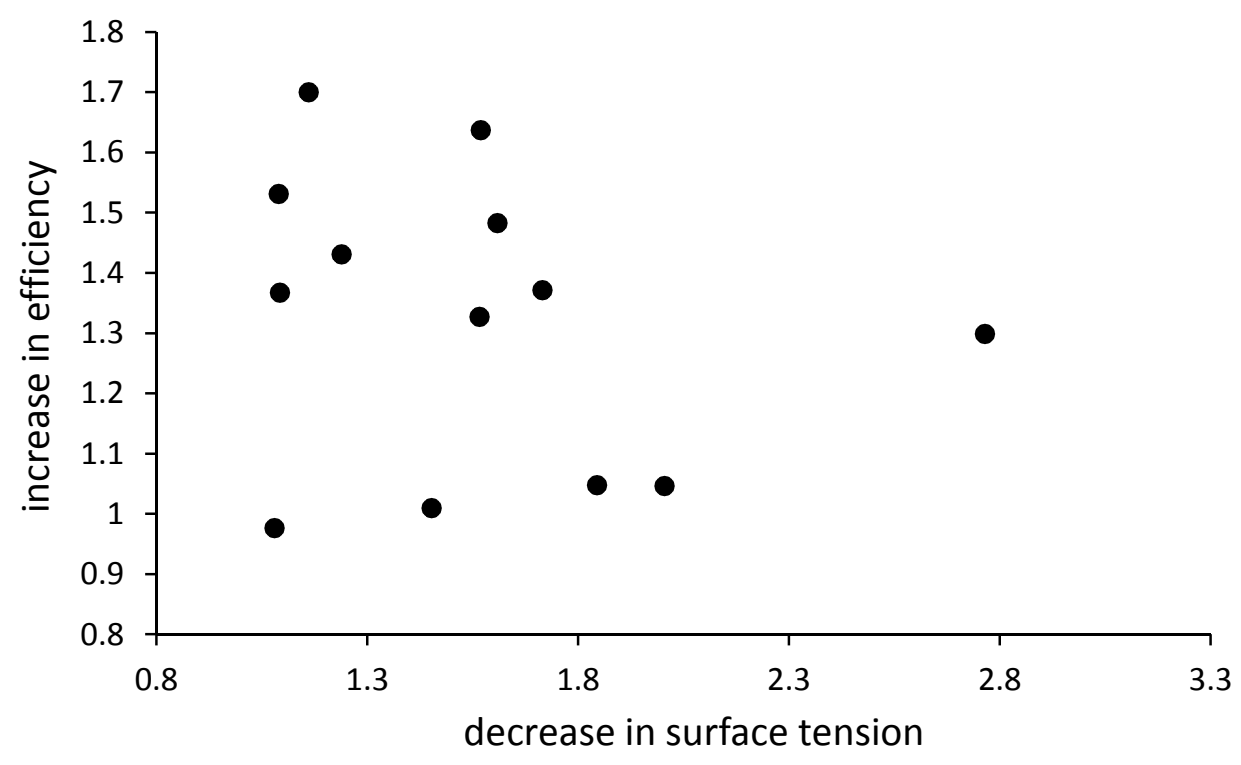

Figure S3. Correlation of the increase in efficiency to the decrease in surface tension. 

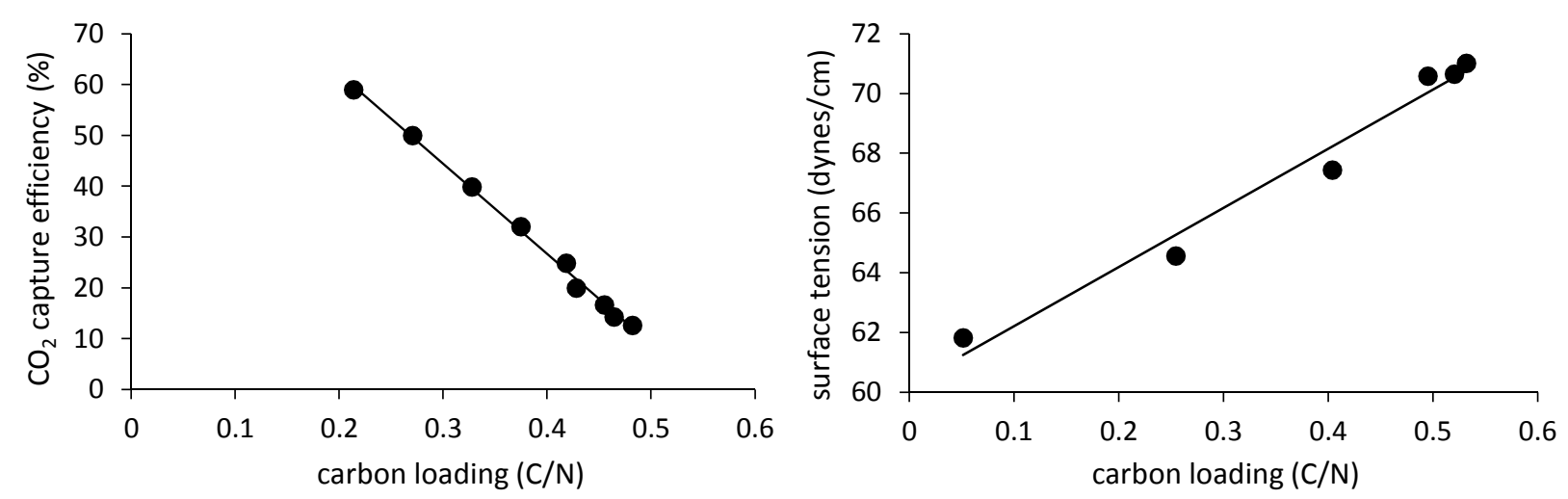

Figure S4. Calibration curves to predict $\mathrm{CO}_{2}$ capture efficiency and surface tension at different carbon loadings for $30 \mathrm{wt} \% \mathrm{MEA}$.

Pressure drop

Pressure drop was measured through a packed column with an ID of 1 in and a packing height of 14 in. A schematic is shown in Figure S5. The gas inlet to the packed column was also sent to one side of a U-tube manometer (Dwyer Flex-Tube). The other end of the manometer was open to the atmosphere, as was the gas outlet from the column. The differential pressures between inlet and outlet were read from the manometer as in $\mathrm{H}_{2} \mathrm{O}$ and then converted to psi. The gas and liquid flow rates were $5 \mathrm{~L} / \mathrm{min}$ and $35 \mathrm{~mL} / \mathrm{min}$, respectively.

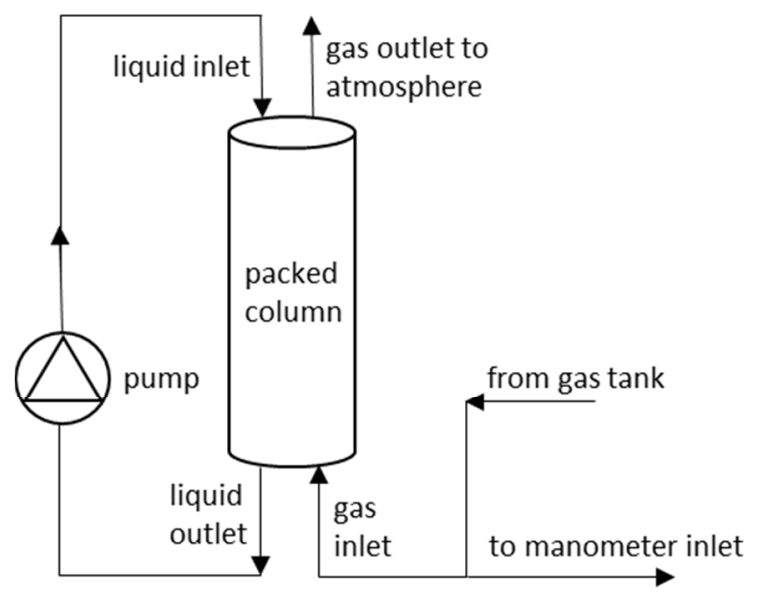

Figure S5. Pressure drop testing apparatus.

\section{Stirred reactor}

Figure S6 shows a schematic of the stirred reactor apparatus. A $250 \mathrm{~mL}$ Erlenmeyer flask was used as the reactor, and the flask was fitted with a rubber stopper with inlet and outlet holes. Approximately $75 \mathrm{~mL}$ solvent was used in the experiments. By using the same volume, the surface area was the same $\left(7.1 \mathrm{in}^{2}\right)$. In a typical experiment, the stirred reactor was placed in a water bath that was maintained at $40{ }^{\circ} \mathrm{C}$ by the magnetic hotplate. Mixed $\mathrm{CO}_{2}$ and $\mathrm{N}_{2}$ gas $(0.75$ 
$\mathrm{L} / \min \mathrm{N}_{2}$ and $0.11 \mathrm{~L} / \min \mathrm{CO}_{2}$ ) was directed into the stirred reactor via a tube above the interface and was blown over the liquid surface while the solution was magnetically stirred. The reactor's outlet gas flow was passed through a condenser in an ice bath and then a bed of Drierite $\left(\mathrm{CaSO}_{4}\right)$ and sent to the $\mathrm{CO}_{2}$ analyzer.

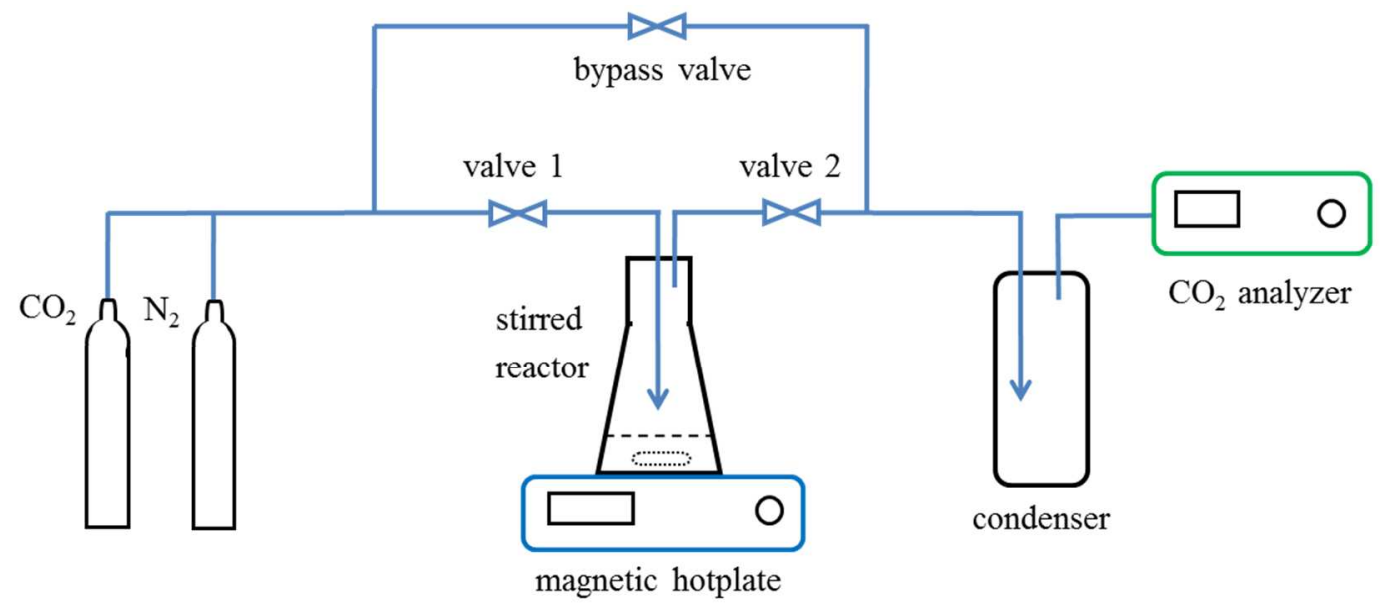

Figure S6. Schematic of the stirred reactor apparatus.

The outlet $\mathrm{CO}_{2}$ concentration data were recorded at $1 \mathrm{~s}$ intervals. The $\mathrm{CO}_{2}$ capture rate was calculated based on the moles of $\mathrm{CO}_{2}$ absorbed as a function of time. The moles of absorbed $\mathrm{CO}_{2}$ $\left(n_{\mathrm{CO} 2}\right)$ was calculated by a summation of the difference in the inlet and outlet $\mathrm{CO}_{2}$ flow rates (Eq. S2).

$$
n_{\mathrm{CO} 2}=\sum\left(\dot{n}_{\mathrm{CO} 2}^{\text {in }}-\dot{n}_{\mathrm{CO} 2}^{\text {out }}\right)
$$

$\dot{n}_{C O 2}^{\text {in }}$ and $\dot{n}_{C O 2}^{\text {out }}$ are the inlet and outlet $\mathrm{CO}_{2}$ molar flow rates, respectively, and the differences at each data interval $(1 \mathrm{~s})$ are summed to get the total amount absorbed as a function of time. The inlet $\mathrm{CO}_{2}$ molar flow rate was calculated based on the volumetric total inlet flow rate, the vol\% $\mathrm{CO}_{2}$ in the inlet gas stream (as measured by sending it directly to the $\mathrm{CO}_{2}$ analyzer), and the ideal gas equation of state. The outlet $\mathrm{CO}_{2}$ molar flow rate was calculated in the same way, using the outlet $\mathrm{CO}_{2} \mathrm{vol} \%$ and the volumetric total outlet flow rate $\left(Q_{\text {out }}\right)$, which was back-calculated (Eq. S3) by assuming that the inlet nitrogen flow rate is equal to the outlet nitrogen flow rate (Eq. S4).

$$
\begin{gathered}
Q_{\text {out }}=Q_{N 2}^{\text {out }} / y_{N 2}^{\text {out }} \\
Q_{N 2}^{\text {out }}=Q_{N 2}^{\text {in }}=Q_{\text {in }} * y_{N 2}^{\text {in }}
\end{gathered}
$$

$y_{N 2}^{\text {in }}$ and $y_{N 2}^{\text {out }}$ are the volume fractions of nitrogen in the inlet and outlet gas streams, respectively.

\section{Wetted wall column}

A schematic of the WWC is shown in Figure S7. In a typical experiment, the amine solvent is first loaded with $\mathrm{CO}_{2}$ to a $\mathrm{C} / \mathrm{N}$ of $\sim 0.1$ by sparging the solution reservoir with a $\mathrm{CO}_{2} / \mathrm{N}_{2}$ mixture 
for a predetermined amount of time. The solution was then heated to the desired temperature by circulating it through a preheater. $\mathrm{A} \mathrm{CO}_{2} / \mathrm{N}_{2}$ gas feed $(5 \mathrm{~L} / \mathrm{min})$ was supplied using AALBORG MFCs with a precision of $0.5 \%$. The gas stream was bubbled through a water saturator, which was maintained at the testing temperature, and then brought into contact with the amine solvent countercurrently on the column surface. The column is a hollow stainless steel rod with a height of $14.8 \mathrm{~cm}$, an OD of $1.26 \mathrm{~cm}$, and a surface area of $58.6 \mathrm{~cm}^{2}$. This column is in a chamber and is uniformly surrounded by 16 orifices through which the gas enters the chamber. The pressure is maintained at slightly higher than atmospheric. The $\mathrm{CO}_{2}$ concentration of the outlet gas stream is measured by a $\mathrm{CO}_{2}$ analyzer. Before reaching the analyzer, water vapor in the gas stream is removed using an ice bath and a Drierite $\left(\mathrm{CaSO}_{4}\right)$ bed. To ensure no $\mathrm{CO}_{2}$ is condensed, the outlet gas stream is passed through a $15 \mathrm{M}$ phosphoric acid trap before the ice bath. Gases with four $\mathrm{CO}_{2}$ concentrations between 2 and 14 vol\% $\mathrm{CO}_{2}$ were tested at each carbon loading. The above procedure was repeated for various carbon loadings.

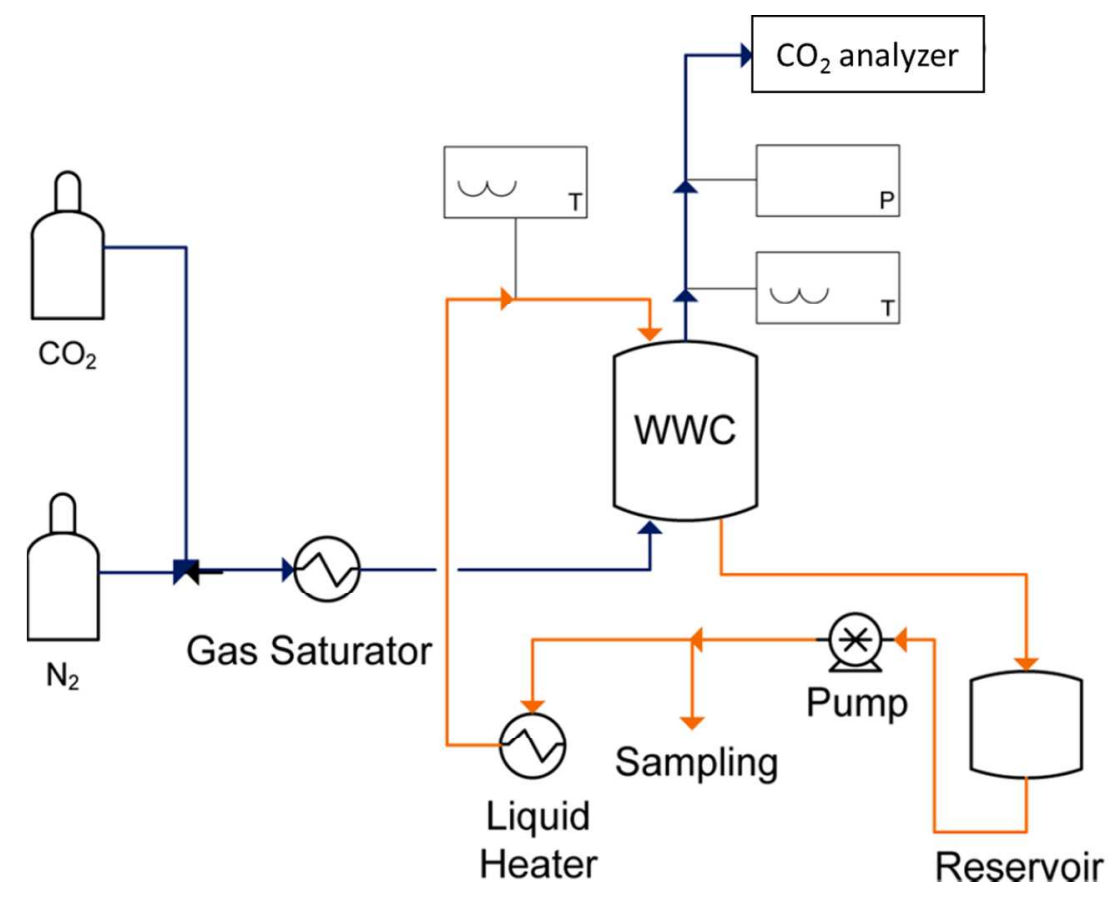

Figure S7. Schematic of the wetted wall column (adapted from ref. 1).

The $\mathrm{CO}_{2}$ mass transfer flux $\left(\mathrm{N}_{\mathrm{CO} 2}\right)$ and the log mean driving force $\left(\triangle \mathrm{P}_{\mathrm{CO} 2}\right)$ are obtained from the $\mathrm{CO}_{2}$ pressure difference. The overall mass transfer coefficient, $K_{G}$, is calculated using these values and the gas-liquid contact area, $A$, as shown in Eq. S5.

$$
K_{G}=\frac{N_{\mathrm{CO} 2}}{A \triangle P_{\mathrm{CO} 2}}
$$

The flux is calculated using the $\mathrm{CO}_{2}$ concentration difference at the inlet and outlet of the WWC as shown in Eq. S6.

$$
N_{C O 2}=\dot{n}_{C O 2}^{\text {in }}-\dot{n}_{C O 2}^{\text {out }}
$$


The $\mathrm{CO}_{2}$ molar flow rates $\left(\dot{n}_{\mathrm{CO} 2}\right)$ were calculated as detailed in the stirred reactor description (see Eq. S2-S4).

To represent the true average differential pressure of $\mathrm{CO}_{2}$, the $\log$ mean driving force was calculated as shown in Eq. S7.

$$
\Delta P_{C O 2}=\frac{P_{C O 2}^{i n}-P_{C O 2}^{o u t}}{\ln \left(\frac{P_{C O 2}^{i n}-P_{C O 2}^{*}}{P_{C O 2}^{o u t}-P_{C O 2}^{*}}\right)}
$$

The partial pressure of $\mathrm{CO}_{2}, P_{\mathrm{CO} 2}$, is calculated using Eq. S8.

$$
P_{\mathrm{CO} 2}^{i}=x_{\mathrm{CO} 2}^{i}\left(P_{\text {total }}-P_{\text {water }}\right)
$$

$P_{\text {total }}$ is the total pressure and $x_{\mathrm{CO} 2}$ is the mole fraction of $\mathrm{CO}_{2}$ determined from the outlet $\mathrm{CO}_{2}$ concentration after drying the gas stream. Because the feed gas is saturated with water, the partial pressure of water, $P_{\text {water }}$, or the saturation pressure at temperature $T$, can be expressed as shown in Eq. S9.

$$
P_{\text {water }}=\exp \left(72.55-\frac{7207}{T}-7.139 \ln (T)+4.046 \times 10^{-6} T^{2}\right)
$$

The equilibrium partial pressure of $\mathrm{CO}_{2}, P_{\mathrm{CO} 2}^{*}$, was calculated by setting the flux to be zero at a driving force of zero through a trial and error routine in MATLAB.

\section{$\mathrm{CO}_{2}$ Solubility}

The solubility of $\mathrm{CO}_{2}$ in $30 \mathrm{wt} \%$ MEA was unaffected by the addition of surfactant as verified by vapor-liquid equilibrium measurements (Figure S8).

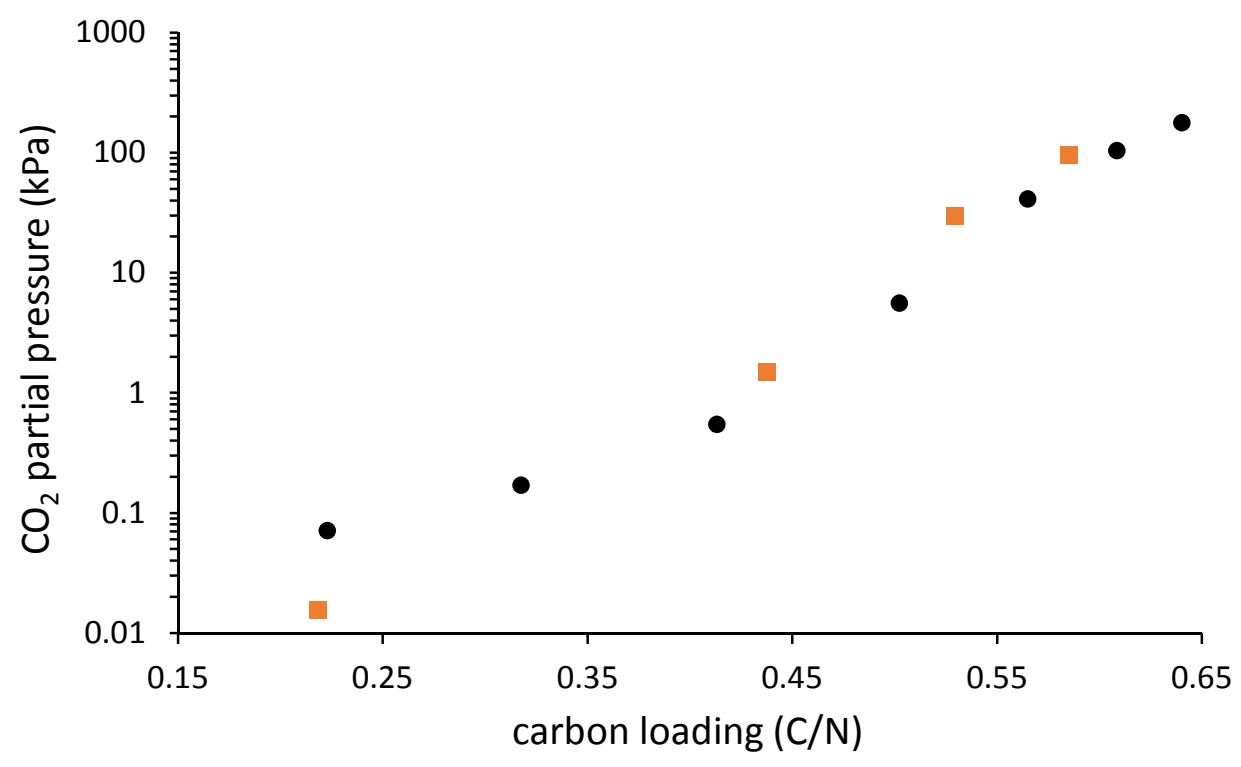

Figure S8. Vapor-liquid equilibrium for $30 \mathrm{wt} \%$ MEA with and without surfactant. $\bullet: 0 \mathrm{wt} \% \mathrm{~S}-$ 554; $0.7 \mathrm{wt} \% \mathrm{~S}-554$. 


\section{Wettability}

Figure S9 shows a picture of the qualitative wetting experimental setup. The experiment was conducted as follows. A ceramic plate was set such that a flow of solvent could be directed downwards across its surface. Flows of 30 wt $\%$ MEA $(250 \mathrm{~mL} / \mathrm{min})$ with varying amounts of surfactant were directed down the ceramic plate. High-speed camera images were taken during this time. The results are difficult to assess from the collected videos and pictures. In person, the hydrophilic solvent could be clearly seen flowing in a finger-like pattern and not as a sheet. No difference in the flow characteristics was detected with $0.01 \mathrm{wt} \%$ surfactant. Only with $0.3 \mathrm{wt} \%$, when the surface tension is dramatically decreased, did the solvent appear to spread more easily over the ceramic surface. The variability of the flow pattern and the coalescence of the finger-like streams prevented any quantitative analysis of these experiments.

To obtain some quantitative data, another experiment was performed to measure wettability. $25 \mu \mathrm{L}$ drops of $30 \mathrm{wt} \%$ MEA with varying amounts of surfactant were placed on ceramic. Two different ceramic plates were used (the one shown in Figure S9 and another), and two areas from each plate were tested. The drop size was measured when it was placed on the plate (time $=0 \mathrm{~s}$ ) and again after 60 and 120

$\mathrm{s}$. The data were averaged, and the increase in the drop size was noted. The percent increase in drop size is termed the spreadability and is considered to be a measure of the wettability of the solvent.

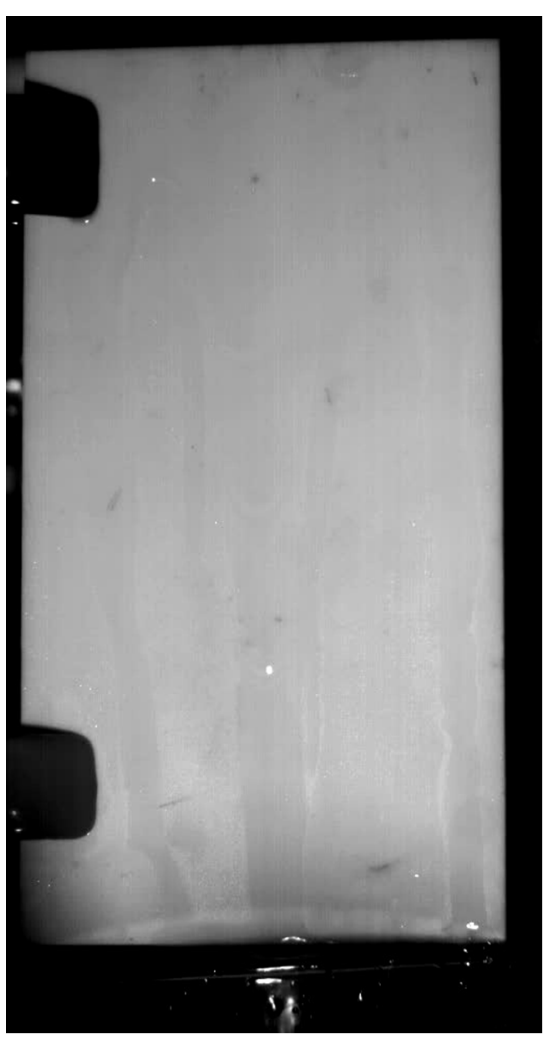

Figure S9. A ceramic plate suspended vertically with $30 \mathrm{wt} \%$ aqueous MEA flowing down it.

Different samples of $30 \mathrm{wt} \%$ MEA with varying amounts of surfactant and at various carbon loadings were tested. The surface tension varies with amount of surfactant and carbon loading, and the spreadability is plotted as a function of surface tension in Figure S10. The collected data are given in Table S1.

Table S1 Drop spreadability data of different solutions of $30 \mathrm{wt} \%$ MEA over ceramic

\begin{tabular}{|c|c|c|c|c|c|c|c|c|c|c|c|}
\hline \multirow{2}{*}{$\begin{array}{l}\text { wt } \% \\
\text { S554 }\end{array}$} & \multirow{2}{*}{$\begin{array}{l}\text { surface tension } \\
(\text { dynes/cm })\end{array}$} & \multicolumn{4}{|c|}{ Plate 1 \#1 drop size (mm) } & \multirow{2}{*}{$\begin{array}{c}\% \\
\text { increase } \\
\end{array}$} & \multicolumn{4}{|c|}{ Plate 1 \#2 drop size (mm) } & \multirow{2}{*}{$\begin{array}{c}\% \\
\text { increase } \\
\end{array}$} \\
\hline & & Os & $30 \mathrm{~s}$ & $60 \mathrm{~s}$ & $120 \mathrm{~s}$ & & $0 \mathrm{~s}$ & $30 \mathrm{~s}$ & $60 \mathrm{~s}$ & $120 \mathrm{~s}$ & \\
\hline 0 & 61.8 & 8.6 & 9.78 & 10.41 & 10.62 & 23.49 & 8.88 & 9.32 & 9.55 & 9.79 & 10.25 \\
\hline 0 & & 9.89 & 10.62 & 10.99 & 11. & 14.36 & 9.13 & 9.85 & 9.69 & 10.02 & 9.75 \\
\hline 0 & & 10.14 & 11.29 & 11.31 & & 15.38 & 7.54 & 8.34 & 8.39 & & 11.41 \\
\hline 0 & & 9.51 & 11.05 & 12.28 & 11.29 & 18.72 & 8.67 & 8.94 & 8.94 & 8.92 & 2.88 \\
\hline 0.01 & & 9.87 & 10.73 & 10.5 & 12.82 & 29.89 & 8.93 & 9.82 & 9.86 & 10.24 & 14.67 \\
\hline 0.01 & 59.9 & 10.55 & 13.2 & 13.03 & 13.71 & 29.95 & 9.47 & 10.17 & 10.44 & 10.57 & 11.62 \\
\hline 0.01 & 62.7 & 10.88 & 11.66 & 12.41 & 12.31 & 13.14 & 11.33 & 12.67 & 12.96 & 13.29 & 17.30 \\
\hline 0.01 & 64.8 & 10.5 & 11.52 & 11.77 & 12.33 & 17.43 & 9.78 & 11.27 & 10.72 & 11.58 & 18.40 \\
\hline
\end{tabular}




\begin{tabular}{|c|c|c|c|c|c|c|c|c|c|c|c|}
\hline 0.05 & 33.211 & 12.49 & 18.69 & 20.55 & 23.32 & 86.71 & 13.03 & 16.03 & 17.67 & 19.84 & 52.26 \\
\hline 0.05 & 38.3325 & 12.44 & 17.08 & 18.62 & 20.81 & 67.28 & 11.74 & 17.69 & 19.92 & 21.96 & 87.05 \\
\hline 0.05 & 42.562 & 11.01 & 12.68 & 14.01 & 15.3 & 38.96 & 10.85 & 13.53 & 15.92 & 16.55 & 52.53 \\
\hline 0.05 & 56.4501 & 11.73 & 13.88 & 14.48 & 15.05 & 28.30 & 11.99 & 14.3 & 4.01 & 14.26 & 18.93 \\
\hline 0.1 & 30.5 & 12.8 & 16.71 & 18.14 & 20.11 & 57.11 & 12.45 & 15.92 & 17.65 & 19.68 & 58.07 \\
\hline 0.1 & 41.8 & 12.2 & 17.48 & 20.77 & 22.14 & 81.48 & 10.97 & 14.17 & 14.89 & 15.9 & 44.94 \\
\hline 0.1 & 43.8 & 11.5 & 17.41 & 18.91 & 21.03 & 82.87 & 10.65 & 12.39 & 13.45 & 13.68 & 28.45 \\
\hline \multirow[t]{3}{*}{0.1} & 47.8 & 12.82 & 15.71 & 15.74 & 15.87 & 23.79 & 10.19 & 12.25 & 11.66 & 11.8 & 15.80 \\
\hline & & \multicolumn{4}{|c|}{ Plate 2 \#1 drop size (mm) } & 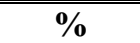 & \multicolumn{4}{|c|}{ Plate 2 \#2 drop size (mm) } & $\%$ \\
\hline & & $0 \mathrm{~s}$ & $30 \mathrm{~s}$ & $60 \mathrm{~s}$ & $120 \mathrm{~s}$ & increase & $0 \mathrm{~s}$ & $30 \mathrm{~s}$ & $60 \mathrm{~s}$ & $120 \mathrm{~s}$ & increase \\
\hline 0 & 61.8 & 10.97 & 13.06 & 13.46 & 14.3 & 30.36 & 11.79 & 14.77 & 15.4 & 16.51 & 40.03 \\
\hline 0 & 64.6 & 9.65 & 10.58 & 10.7 & 10.89 & 12.85 & 10.77 & 13.4 & 13.73 & 14.92 & 38.53 \\
\hline 0 & 67.4 & 11.79 & 14.29 & 15.58 & 17.11 & 45.12 & 10.5 & 13.35 & 14.44 & 15.66 & 49.14 \\
\hline 0 & 70.6 & 10.37 & 12.4 & 12.66 & 12.79 & 23.34 & 12 & 16.78 & 17.49 & 19.2 & 60.00 \\
\hline 0.01 & 56.6 & 13.45 & 17.59 & 20.05 & 22.5 & 67.29 & 12.01 & 15.41 & 17.49 & 19.65 & 63.65 \\
\hline 0.01 & 59.9 & 12.13 & 14.84 & 15.07 & 15.56 & 28.28 & 13 & 16.67 & 17.75 & 19.71 & 51.62 \\
\hline 0.01 & 62.7 & 12.91 & 16.77 & 17.4 & 17.97 & 39.19 & 11.44 & 14.64 & 16.53 & 18.39 & 60.75 \\
\hline 0.01 & 64.8 & 12 & 14.97 & 16.16 & 16.37 & 36.42 & 12.55 & 15.46 & 17.78 & 19.11 & 52.27 \\
\hline 0.05 & 33.211 & 13.5 & 18.89 & 20.87 & 24.57 & 82.00 & 11.66 & 16.57 & 19.01 & 22.39 & 92.02 \\
\hline 0.05 & 38.3325 & 13.15 & 19.46 & 20.44 & 22.28 & 69.43 & 11.97 & 16.96 & 19.6 & 21.69 & 81.20 \\
\hline 0.05 & 42.562 & 12.07 & 16.72 & 18.2 & 20.53 & 70.09 & 12.06 & 15.79 & 16.75 & 18.32 & 51.91 \\
\hline 0.05 & 56.4501 & 13.19 & 16.36 & 18.02 & 20.06 & 52.08 & 12.47 & 17.79 & 19.01 & 20.27 & 62.55 \\
\hline 0.1 & 30.5 & 12.12 & 16.35 & 17.28 & 19.42 & 60.23 & 12.89 & 17.58 & 18.46 & 21.01 & 62.99 \\
\hline 0.1 & 41.8 & 15.03 & 20.02 & 22.34 & 24.63 & 63.87 & 13.49 & 18.2 & 21.33 & 23.73 & 75.91 \\
\hline 0.1 & 43.8 & 12.33 & 16.64 & 19.52 & 21.02 & 70.48 & 12.16 & 18.81 & 19.78 & 21.11 & 73.60 \\
\hline 0.1 & 47.8 & 12.85 & 16.36 & 16.93 & 17.71 & 37.82 & 11.5 & 14.22 & 14.97 & 15.68 & 36.35 \\
\hline
\end{tabular}

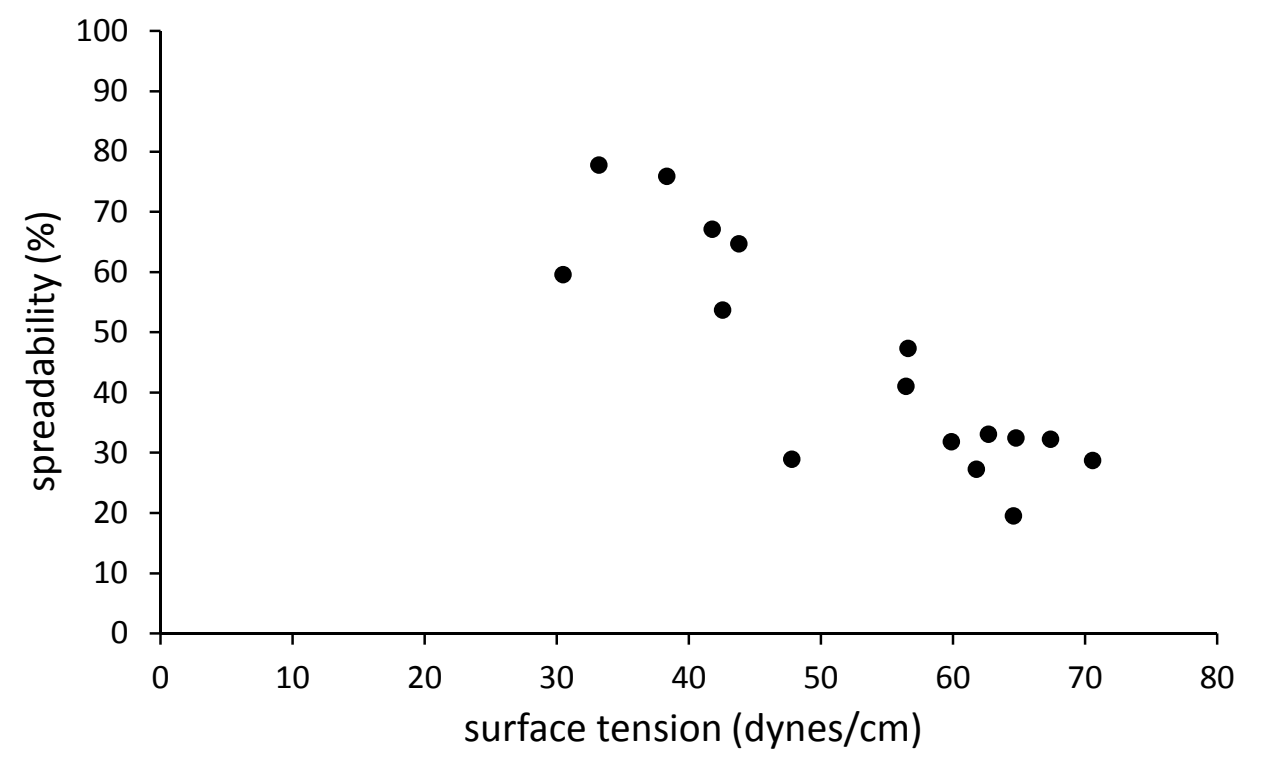

Figure S10. Correlation of the spreadability on ceramic of $25 \mu \mathrm{L}$ drops of $30 \mathrm{wt} \%$ MEA with varying amounts of surfactant and varying carbon loadings as a function of the surface tension.

Bubble column 
The apparatus for the bubble column experiments is depicted in Figure S11. In a typical experiment, simulated flue gas is passed $\left(0.75 \mathrm{~L} / \mathrm{min} \mathrm{N}_{2}, 0.11 \mathrm{~L} / \mathrm{min} \mathrm{CO}_{2}\right)$ through water (the saturator) and then through the bubble column using glass impingers. The system (saturator and column) is heated by immersion in a water bath. The outlet gas is passed through a condenser in an ice bath and dried through a bed of Drierite before being sent to the $\mathrm{CO}_{2}$ analyzer. The outlet $\mathrm{CO}_{2}$ concentration data were recorded at $1 \mathrm{~s}$ intervals. The $\mathrm{CO}_{2}$ capture rate was calculated based on the inlet and outlet $\mathrm{CO}_{2}$ flow rates as a function of time using the same method detailed in the stirred reactor section.

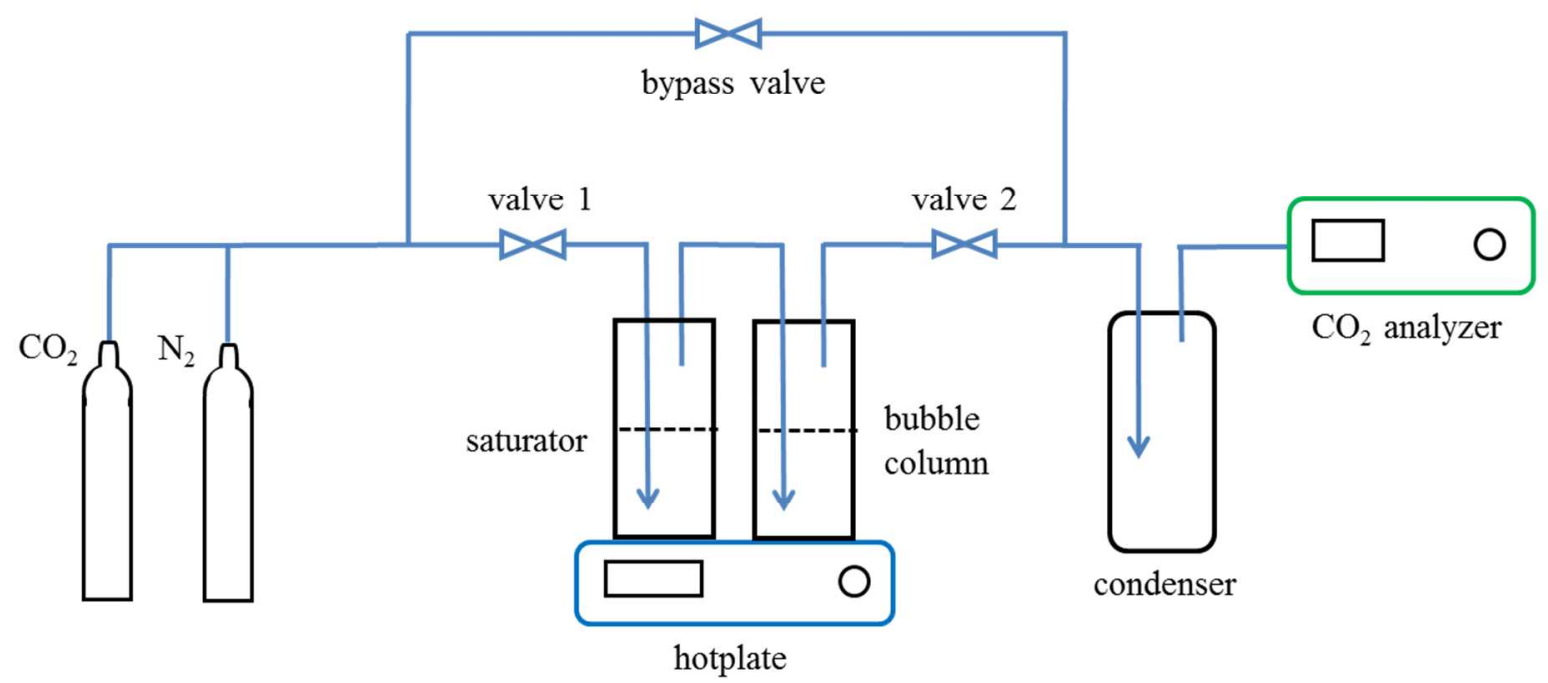

Figure S11. Schematic of the bubble column experimental apparatus.

\section{References}

1. Matin, N. S.; Remias, J. E.; Neathery, J. K.; Liu, K. Facile Method for Determination of Amine Speciation in $\mathrm{CO}_{2}$ Capture Solutions. Ind. Eng. Chem. Res. 2012, 51 (19), 6613-6618. 